\title{
LA ESTRATEGIA SIMBÓLICA ANTE AMENAZAS NATURALES Y DESASTRES ENTRE ESPAÑA Y MÉXICO
}

\author{
RAYMUNDO PADILLA LOZOYA \\ Universidad de Colima (México) \\ rpadilla@ucol.mx
}

Canción popular

¡Que llueva que llueva, la Virgen de la Cueva, los pajarillos cantan, las nubes se levantan, que sí, que no, que caiga un chaparrón! (Lera, 1983: 158)

\section{Resumen}

El presente artículo pone en diálogo distintas investigaciones y reflexiones históricas relacionadas con la dimensión simbólica de la protección ante amenazas hidrometeorológicas a partir del siglo XV. Por medio del método histórico y comparativo se evidencia entre España y México lo que puede caracterizarse como una estrategia adaptativa simbólica compuesta por expresiones culturales materiales y manifestaciones de la espiritualidad con el propósito de enfrentar fenómenos naturales considerados amenazantes o extremos. Como fuentes se utilizan publicaciones especializadas y documentación histórica que permiten argumentar la existencia de una estrategia compuesta por tres variables fundamentales: planeación, escala y frecuencia. Como resultado se considera a la ritualidad y a los patronazgos como elementos de una de las más elaboradas estrategias simbólicas para manejar las crisis populares por desastre, enfrentar amenazas naturales, fortalecer la cohesión social y favorecer la resiliencia.

Palabras clave: Estrategia, Patrono, Desastre, Adaptación, Amenaza, Religiosidad. 


\begin{abstract}
Symbolic Strategy for Natural Threats and Disasters between Spain and Mexico

This article links different investigations and historical reflections about the symbolic dimension of protection against hydrometeorological threats from the 15th century. With the historical and comparative method it is evident between Spain and Mexico what can be characterized as a symbolic adaptive strategy composed of cultural expressions and manifestations of spirituality with the purpose of facing natural phenomena considered threatening or extreme. Specialized publications and historical documentation are used to argue the existence of a strategy composed of three fundamental variables: planning, scale and frequency. As a result, we consider some rituals and patrons as elements of one of the most elaborate symbolic strategies to handle popular crises by disaster, coping natural threats, strengthen social cohesion, and create resilience.
\end{abstract}

Keywords: Strategy, Patronage, Disaster, Adaptation, Threat, Religiosity.

\title{
Introducción
}

Todas las culturas antiguas se enfrentaron a manifestaciones extremas de la naturaleza y buscaron distintas formas de explicar las convulsiones del entorno con expresiones culturales que en muchos casos aún sobreviven. Por medio del animismo asignaron a los fenómenos naturales un espíritu o alma responsable de cada acción en el entorno. De esta manera crearon un discurso que les permitió obtener una cosmovisión para comprender y sobrevivir a los eventos percibidos como amenazantes y mortales. El animismo estableció una comunicación entre el espíritu del humano y el espíritu de la montaña, del río, del volcán, del huracán, que ha sido documentada en diversas investigaciones arqueológicas, antropológicas e históricas ${ }^{1}$. Así, es posible encontrar comparativos entre las culturas, por ejemplo, los maoríes se han enfrentado a lo largo de su historia con violentas erupciones volcánicas, sismos, tsunamis, deslizamientos de laderas y huracanes ${ }^{2}$. Para los primeros maoríes la naturaleza se componía de seres especiales que estaban fuera de

1. Véase: LeÓn-Portilla, 1992. WAChtel, 2001. Petit-Breuilh Sepúlveda, 2006. Gascón, 2005. LORENTE Y FERNÁNDEZ, 2011.

2. Véase: MCFADGEN, 2007.

Revista de Historia Moderna, n. 35 (2017) (pp. 116-148) | ISSN-e: 1989-9823 | ISSN: 0212-5862 
su control, eran parte de lo sobrenatural y solo se podían controlar por medio de actos religiosos ${ }^{3}$. Por ello desarrollaron un conjunto de manifestaciones rituales y simbólicas para honrar a las deidades, pedir su clemencia y obtener beneficios como la sobrevivencia y los alimentos. De esta manera, su cosmovisión incluyó una protección simbólica que les aportó certidumbre a pesar de los peligros que caracterizan a sus islas. Con ese esquema permanecieron en las islas por siglos y dieron explicaciones al funcionamiento natural, al cual estaban estrechamente vinculados.

El esquema animista es característico de la mayoría de las culturas indígenas. En el caso del continente americano, el animismo fincó las bases de las complejas creencias de las más avanzadas culturas, como la maya, mexica, inca y azteca. Sin embargo, algunas deidades eran bélicas e imponían castigos. Como lo señala Petit-Breuilh, para los nativos, los dioses utilizaban los elementos naturales -agua, fuego, tierra y aire- como castigos a la humanidad por considerar que no se les rendía culto adecuadamente, y en ciertas circunstancias la ira del dios constituía la causa de algún desastre, el cual solo se podía apaciguar por medio de la purificación, el sacrifico y rituales que todavía se practican en algunos grupos indígenas y que han sido documentados por la historia, la antropología del clima y la etnometeorología en Centroamérica y Sudamérica ${ }^{4}$.

Por lo anterior, es notable que la presencia de diversos fenómenos naturales, considerados como amenazas por algunas sociedades, ha influido en los comportamientos y maneras de relacionarse entre los humanos y la naturaleza, dando como resultado expresiones simbólicas y materiales muy particulares en cada cultura ${ }^{5}$. En este sentido, el presente artículo pretende abonar a la teoría de los desastres y, en particular, a su relación con la dimensión simbólica, con un enfoque histórico, haciendo énfasis en las manifestaciones rituales y religiosas vinculadas con ciertos fenómenos hidrometeorológicos

3. Véase: LOWE, NeWNHAM y MCCRAW, 2002: 126-161.

4. Véase: Glockner, 1996; 2000, AlbORES, y Broda (Coords.), 2003. Goloubinoff, Katz y LAMMEL (eds.), 1997. LAMMEL, GOLOUBINOFF y KATZ (eds.), 2008.

5. Véase: Bennett, 1976. Viazzo, 1989. Oliver-Smith, y Hoffman (eds.), 1999. PetitBreuilh Sepúlveda, 2006. Arrioja, y Alberola (eds.), 2016, Padilla lozoya, 2014; 2016. 
como las sequías, heladas, granizadas, inundaciones, tormentas severas y ciclones tropicales.

El tema es relevante porque en la teoría interdisciplinaria de los desastres la religión y la espiritualidad son elementos que forman parte de la denominada resiliencia comunitaria. Se ha documentado en algunos desastres que la religión es un importante enlace que fortalece la ayuda y el apoyo entre los afectados; sin embargo, las variables en el comportamiento social están relacionadas con el tipo de cultura que caracteriza a cada sociedad o grupo, e individuos $^{6}$. Según Etkin, en las comunidades religiosas afectadas por desastres existen ciertas ventajas con relación a grupos no creyentes; suele presentarse la esperanza de un mejor futuro, existe el propósito de mejorar, se facilita «la integración psicológica, la esperanza y motivación, el empoderamiento personal, un sentido de control, proporciona modelos para el sufrimiento, orienta en la toma de decisiones, apoyo social y crea sentimientos de autoeficacia. El efecto varía según la cultura...» ${ }^{7}$.

En algunos casos, los grupos religiosos enfrentan las crisis con cierta dependencia en un poder superior, es decir, divino, al cual culpan de la tragedia, pero también le encomiendan el porvenir con la promesa de mejorar como sociedad, lo que evidencia un carácter resiliente. Por lo anterior, aunque las intervenciones en crisis por desastres suelen realizarse primordialmente desde un enfoque técnico y paliativo, también debe considerarse la dimensión espiritual de largo alcance que ha interactuado por años y siglos con la sociedad y con cada uno de los afectados; a pesar de que sea diferencial el grado de vinculación espiritual.

De manera general, todas las religiones son redes vinculadas con cierto capital social y de múltiples maneras; algunas menos organizadas y otras más planificadas o estratégicas. En la base es notable la integración como grupo por medio de coincidencias ideológicas, pero también por medio de metas a corto, mediano y largo plazo que permiten fortalecer la red y construir materialmente los espacios físicos para la ritualización y eventos que contextualizan la socialización; y dependiendo del grado de sociabilidad que existe en cada grupo es el apoyo que se recibe durante las etapas de crisis y

6. ETKIN, 2016: 131 .

7. ETKIN, 2016: 134.

Revista de Historia Moderna, n. ${ }^{\circ} 35$ (2017) (pp. 116-148) | ISSN-e: 1989-9823 | ISSN: 0212-5862 
rehabilitación post desastre. Así, para Etkin, en las culturas más creyentes debe incorporarse la religiosidad como un factor que determina la resiliencia de manera significativa. En síntesis, si omitimos la espiritualidad de los seres humanos en su comprensión y explicación de una tragedia y en su integridad para enfrentar la crisis se excluye un elemento importante que brinda fortaleza a la condición humana. El proceso inicia por medio de la fe, la esperanza y el anhelo a una perspectiva de futuro, sin los cuales sería imposible dar continuidad al proceso de desarrollo social ante el escenario que se percibe en una devastación o tragedia. Al menos en Occidente, la dimensión simbólica es intrínseca a la cultura, aunque las diferentes expresiones religiosas dependen de las preferencias que adopta y adapta cada grupo social en su devenir histórico, lo que explica en parte los antecedentes, el grado de vinculación, el arraigo y la actualización de los rituales.

\section{Ritualidad y desastres}

Desde tiempos antiguos se han documentado creencias relacionadas con seres divinos causantes de manifestaciones que superaban las capacidades humanas, como se leerá en este documento. Pero pocas investigaciones han tratado de manera específica los desastres y la religiosidad, porque esta última se ubica en el marco de la cultura, y por extraño que parezca, como lo precisa Krüger, la cultura vinculada a los desastres ha recibido poca atención como objeto de investigación en los últimos cincuenta años ${ }^{8}$. Por lo anterior, en el presente artículo se hace énfasis en ciertas expresiones culturales y religiosas asociadas a desastres, relacionando evidencia histórica y antropológica.

El procedimiento metodológico comparativo propuesto en este artículo se enfoca en analizar de manera general la relación entre religión y desastres y en particular distintas respuestas efectuadas en los últimos cinco siglos en España y en México. Se parte del estudio de Elaine Fulton acerca de los desastres y la confesionalización, donde propone que en los siglos XVI y XVII, el pensamiento religioso europeo no se diferenció de manera notable con relación a la causa de los desastres, y para católicos, luteranos y calvinistas, Dios

8. KRÜGER et. al., 2015: 4.

Revista de Historia Moderna, n. ${ }^{\circ} 35$ (2017) (pp. 116-148) | ISSN-e: 1989-9823 | ISSN: 0212-5862 
enviaba un doloroso mensaje, la purificación con el castigo y la posibilidad de redimirse por medio del buen camino.

La comprensión popular de por qué sucedieron los desastres naturales en particular no difirió marcadamente de católica a luterana a calvinista: Dios y solo Dios fue el principal impulsor de la naturaleza, y fue su mano la que finalmente dirigió el camino de toda la creación. Por lo tanto, el desastre natural era ampliamente considerado como un llamado divino al arrepentimiento urgente por parte de la humanidad pecaminosa, a medida que el fin del mundo se acercaba cada vez más ${ }^{9}$.

La ritualidad y las explicaciones teológicas de los desastres antecedieron a las respuestas técnicas y científicas del siglo XVI. Posteriormente, la Ilustración y el desarrollo de instrumentos permitieron identificar las características físicas de diferentes fenómenos naturales para registrarlos. Aun así, las respuestas rituales católicas mostradas en el presente artículo fueron, por siglos, comunes entre España y México, mientras que en otros países cristianos cambiaron notablemente y dejaron de ser un evento público y masivo; por ejemplo, en Francia, donde se han documentado escasas procesiones por desastres en el siglo XVII ${ }^{10}$.

Actualmente, la ritualidad y religiosidad en los desastres es estudiada de manera innovadora en algunos centros de investigación, como el Center for Religious and Cross-cultural Studies, ubicado en Yogyakarta en Central Java, Indonesia. En este centro de investigaciones la religión y los desastres se han convertido en objeto de estudio desde que padecieron, en el año 2004, uno de los mayores tsunamis de la historia mundial, un sismo en mayo de 2006 y la destructiva erupción del monte Merapi entre octubre y noviembre de 2010. $\mathrm{Al}$ analizar las respuestas sociales se percataron de la profunda base religiosa y espiritual en que se sostiene el razonamiento cultural. Cabe precisar que para algunos antropólogos, como Rushton Coulborn y Joseph Tainter, es relevante comprender la dimensión religiosa porque de ella ha dependido en parte el colapso de algunas civilizaciones, debido a que «la religión puede

9. FULTON, 2012: 54.

10. QUENET, 2012: 100. 
ser la fuente del declive, pues una sociedad mantiene su fuerza mientras su religión es vigorosa, y la pierde cuando el compromiso religioso se debilita» ${ }^{11}$.

\section{La incorporación de la religiosidad como objeto de estudio en los desastres}

La comprensión actual de los desastres y su relación con la religiosidad ha transitado por un largo recorrido discontinuo, ya que su análisis académico comenzó en la década de los cincuenta del siglo XX. El estudio académico norteamericano de los desastres se inició de manera formal y con rigor científico después de la Segunda Guerra Mundial porque en dicho conflicto se hizo evidente la construcción de desastres por agente antrópico. Sin embargo, la mayoría de las investigaciones de los fenómenos naturales y desastres se realizaban desde las ciencias naturales, así como con la intención de profundizar en las características físicas de la naturaleza por medio de la instrumentación, para conocer los patrones de frecuencia, efectos e impactos. Por su parte, la comprensión de los desastres como eventos que relacionan invariablemente a una sociedad se fortaleció en la segunda mitad del siglo xx con el aporte de múltiples estudios realizados por geógrafos, sociólogos, psicólogos y algunos antropólogos e historiadores.

Así, primero se puso atención en las conductas sociales y psicológicas, y se procuró entender cómo funcionaba la sociedad y qué ocasionaba el desastre. En la década de los cincuenta, la antropología y el trabajo etnográfico se interesaron en analizar la organización social de los grupos tribales de las islas del sudeste del océano Pacífico, y durante las estancias de campo, los antropólogos documentaron las respuestas sociales ante la emergencia y describieron brevemente cómo se relacionaban con la religión. Son ejemplares los estudios realizados en el año de 1957 por David Schneider en la isla de Yap, y los de James Spillius en la isla de Tikopia, y dos años después en el mismo sitio, Raymond Firth. ${ }^{12}$

En la década de los sesenta algunos sociólogos, geógrafos y psicólogos norteamericanos realizaron investigaciones relacionadas con los comportamientos y reacciones sociales asociadas principalmente a los riesgos

11. Véase: TAINTER, 1988: 81.

12. Véase: SCHNEIDER, 16/2 (1957). SPILLIUS, 10/1 (1957). FIRTH, 1959. 
tecnológicos, la contaminación, la energía nuclear y otros agentes nocivos para la salud pública ${ }^{13}$. El progreso de varios proyectos permitió el surgimiento de centros de investigación como el Disaster Research Center (DRC) y el Institute of Behavioral Science, los cuales fueron financiados por agencias gubernamentales con intereses específicos que se extendieron a la década de los setenta. De esta manera, algunos geógrafos comenzaron a documentar el comportamiento social en situaciones de emergencia, con el fin de desarrollar estrategias de control sobre tales circunstancias. En particular, con relación a la religión y los desastres, pocos estudios aportaron datos sobre rituales religiosos, la mayoría omitió la relevancia de las divinidades en la explicación popular de los fenómenos hidrometeorológicos extremos.

El trabajo realizado desde la sociología, la psicología y la geografía, durante la década de los ochenta, se enfocó en gran medida en recolectar información con propósitos cuantitativos y económicos, además de monitoreo y tipificación de las distintas amenazas y desastres. Así, la incorporación de la tecnología se impuso y determinó un primer modo de conocer las amenazas naturales, aunque no se desarrolló en profundidad la reflexión crítica hacia los factores sociales que son la base de los desastres. En pocas palabras, la geografía y la sociología tardaron décadas en evidenciar las relaciones sociales históricas de los fenómenos naturales y las causas de los desastres, toda vez que se impuso en estas disciplinas una visión ahistórica e incluso antihistórica de los desastres, como lo señala García Acosta ${ }^{14}$. Sin embargo, se realizaron algunas aportaciones aisladas que incorporaron una perspectiva diacrónica en el registro de los eventos naturales y sentaron las bases de la perspectiva histórica analítica del proceso constructivo y cultural del riesgo y de los desastres.

Las primeras aportaciones diacrónicas se realizaron para subsanar una evidente falta de perspectiva histórica en el estudio de las amenazas y los desastres, y para explicar desde cuándo se comenzaron a construir los riesgos que anteceden los desastres ${ }^{15}$. Se efectuaron indagaciones diacrónicas y sincrónicas para comparar sociedades de un mismo lugar en distintos momentos y para analizar los cambios en las respuestas de los distintos grupos sociales.

13. Véase: Dynes, De Marchi y Pelanda (eds.), 1990. Quarantelli, 1998.

14. GARCÍA ACOSTA, 2002: 49.

15. Véase: ClaXton, (ed.), 1986.

Revista de Historia Moderna, n. ${ }^{\circ} 35$ (2017) (pp. 116-148) | ISSN-e: 1989-9823 | ISSN: 0212-5862 
Se identificó una ausencia de información sistematizada y se promovió la creación de bases de datos de fenómenos naturales y de desastres ${ }^{16}$. De esta manera se comenzó a producir una historia académica de los desastres, más analítica y crítica de las relaciones sociales con el medio ambiente; las amenazas y la base de las causas de los sucesos desastrosos, exponiendo las múltiples respuestas sociales y los problemas locales, regionales e internacionales que plantea cada caso de estudio.

Entre las publicaciones que marcaron un nuevo rumbo en los estudios históricos de amenazas y desastres en el continente americano, fue pionera la editada en 1986 por el historiador Robert H. Claxton para la revista Studies in the Social Sciences, en la que fueron incluidas algunas investigaciones, entonces muy recientes y representativas. La revista fue publicada en Norteamérica, pero los artículos incorporados tratan casos ocurridos en Centro y Sudamérica con relación a las respuestas sociales ante las epidemias como el Matlazáhuatl de 1737-1738 en Guadalajara, epidemias en Brasil en 1890-1940 y temblores en Chile, Centroamérica y Perú en 1970.

La revista editada por Claxton es uno de los primeros estudios en establecer desde una perspectiva histórica, que «las amenazas naturales se vuelven ‘desastres naturales` cuando la población no quiere o no entiende cómo hacer frente a su medio ambiente» ${ }^{17}$. Claxton comprendió que los fenómenos naturales intensos se han presentado repetidamente en la historia de Latinoamérica y que una de las constantes en el pasado es la periódica ocurrencia de estos devastadores desastres. Consideró que estos eventos son de competencia de la historia y notó que los historiadores tratan a los desastres como parte del fondo de otros temas o como un evento agravante, sin darle la importancia adecuada en los procesos de cambio social.

Claxton observó que en la historia de las amenazas naturales en Latinoamérica no existían estudios del período colonial al presente, y propuso con la revista rectificar la falta de perspectiva histórica del análisis de las amenazas naturales en América Latina, presentando diversos casos y ofreciendo

16. Véase: Desinventar. Disponible en: http://www.desinventar.org/es/ [consultado el 12 de diciembre de 2016] y EM-DAT: The OFDA-CRED International Disaster Database, Université Catholique de Louvain, Bruselas. Disponible en: http://www.emdat.be [consultado el 12 de diciembre de 2016].

17. Claxton, (ed.), 1986: III. 
datos de su repetida ocurrencia a lo largo de amplios períodos de tiempo. Entre los estudios recopilados se realizaron análisis de la mayor epidemia del siglo XVIII en México y de las enfermedades que diezmaron a la población afrobrasileña entre 1890 y 1940 . Se recopilaron los informes de temblores de mayor y menor escala en Chile. Se expuso un análisis de las ventajas y desventajas del desastre entre los yungaínos de Perú. Se describieron los sistemas para prevenir inundaciones y sequías en Bolivia y Guatemala, y en el último documento, se hizo una distinción entre sequías climatológicas, meteorológicas y sociopolíticas. En conjunto se coincidió en que ciertas respuestas institucionales se han presentado en distintos desastres, como exentar impuestos y brindar auxilios, y que estas han sido mayormente implementadas ante los impactos de sequías que cuando ocurren inundaciones. Posterior a la revista editada por Claxton, las recopilaciones de estudios históricos de desastres y las revistas multi-temáticas se volvieron un recurso eficiente para la difusión del conocimiento en Latinoamérica.

En la década de los noventa, las Naciones Unidas promovieron el Decenio Internacional para la Reducción de Desastres Naturales (DIRDN) y en ese marco internacional se fomentó el interés y financiamiento para diversos proyectos, principalmente instrumentales, de monitoreo y alertamiento temprano, de gran impacto, que aportaron múltiples recomendaciones y experiencias a nivel global, algunas recogidas por publicaciones especializadas y técnicas. ${ }^{18}$ En la misma década, pero en Costa Rica, Naciones Unidas amparó la conformación de un grupo llamado La RED (Red de Estudios Sociales en Prevención de Desastres en América Latina), como respuesta a la tecnocratización de las amenazas y desastres. Desde La RED, diversos académicos, instituciones y grupos no gubernamentales de diferentes países promovieron el estudio social de los riesgos y desastres; en particular en los países considerados menos desarrollados o en desarrollo, principalmente de Latinoamérica. La RED propuso un enfoque constructivista que profundizó en los antecedentes históricos y las relaciones sociales, políticas, culturales y medioambientales, para explicar la construcción social del riesgo y del desastre. Desde este enfoque se hizo evidente que, aunque algunos fenómenos son destructivos,

18. Véase: ZSCHAU y KÜPPERS, 2003.

Revista de Historia Moderna, n. ${ }^{\circ} 35$ (2017) (pp. 116-148) | ISSN-e: 1989-9823 | ISSN: 0212-5862 
no todos son devastadores, ya que la vulnerabilidad es el agente social activo que determina el grado de cada desastre.

En los primeros estudios históricos de desastres pasaban años entre una publicación y otra, pero con la Década Internacional para la Reducción de los Desastres Naturales se hicieron más consistentes los productos y los aportes. Desde la década de los noventa, en el seno de La RED se produjeron tres volúmenes con compilaciones tituladas Historia y Desastres en América Latina, que estudiaron una amplia variedad de casos asociados a diversas amenazas. En esas publicaciones se debatieron, reafirmaron y aplicaron los planteamientos teórico-conceptuales de esa red de investigadores. Se privilegió la perspectiva histórica para explicar múltiples fenómenos socio-culturales como las migraciones, respuestas ante desastres, percepciones de riesgos y amenazas; interpretaciones de la naturaleza, auxilios, estrategias adaptativas ante amenazas y prácticas para hacer frente a emergencias en diferentes escenarios desastrosos. En La RED se realizaron varios números de la revista Desastres $\mathcal{E}$ Sociedad, en la cual se incluyeron artículos de colaboradores internacionales multidisciplinarios, con resultados de investigaciones principalmente realizadas en Centro y Sudamérica, con relación al marco conceptual de La RED, el cual fue muy influyente para los estudios latinoamericanos. Desde la perspectiva de esta red, los desastres no han sido actos de Dios, ni de la naturaleza, son actos del hombre y problemas producidos por el desarrollo inequitativo, inadecuado e impuesto de ciertos modelos económicos y políticos, pero se relacionan profundamente con las diversas relaciones con la naturaleza y con las expresiones culturales, creencias religiosas y las explicaciones naturalistas de cada grupo social.

En México y en España, durante la década de los noventa se iniciaron los estudios históricos de los desastres y su vinculación con elementos de religiosidad ${ }^{19}$. Posteriormente, se desarrollaron esporádicas publicaciones sobre desastres y las respuestas civiles y religiosas. En México, la historiadora América Molina del Villar escribió en 1996 el ensayo más amplio y detallado de la relación entre las amenazas naturales, los desastres y las manifestaciones

19. En España es reciente el estudio histórico de los desastres, según lo señala María de los Ángeles Pérez Samper, quien precisa que el trabajo pionero estudió los terremotos del año 1373 en los Pirineos. Véase: Olivera et. al., 1994, y PÉREZ SAMPER, 2009: 131-208. 
sociales y religiosas entre los años 1700 a 1762. El ensayo de Molina del Villar es pionero en el análisis de las expresiones religiosas, civiles y clericales asociadas con amenazas naturales y desastres reportados en la Ciudad de México. Su metodología analiza la importancia que asignaban las autoridades civiles y religiosas a los actos y conmemoraciones religiosas para enfrentar amenazas naturales. Pone atención en la frecuencia de sucesos amenazantes reportados en fuentes oficiales, la reglamentación de las festividades, las características de los eventos rituales, la calendarización litúrgica, los mitos y rituales particulares, los espacios de celebración y los adornos que engalanaban las calles. Es un documento que facilita contrastar lo que se efectuaba en la capital en relación con los estudios que pudieran realizarse sobre estos temas en poblaciones del exterior de la metrópoli. Después del estudio de Molina del Villar se han publicado producciones históricas y antropológicas que muestran evidencias de manifestaciones religiosas, principalmente relacionadas con desastres detonados por sismos ${ }^{20}$; sin embargo, la religiosidad vinculada a los desastres asociados a fenómenos hidrometeorológicos ha pasado casi inadvertida en los estudios académicos.

\section{La perspectiva comparada}

En México es conveniente analizar la religiosidad y los desastres asociados a fenómenos hidrometeorológicos de manera comparativa e integradora porque está intrínseca en la cultura nacional sincretizada con elementos nativos e iberoaméricos. A pesar de los esfuerzos realizados por los españoles y criollos para eliminar todo rastro de idolatría en América, en las conmemoraciones religiosas perduraron símbolos particulares, por ejemplo, en las danzas de

20. En México, al iniciar el siglo Xxi fue publicado Los sismos en la historia de México, tomo II: el análisis social, en el cual se mencionan diversas prácticas religiosas relacionadas con la protección contra sismos. Véase García Acosta, 2001. Posteriormente, El Colegio de Michoacán dedicó un número a la religiosidad y los desastres. Entre los temas, Charles F. Walker trató las premoniciones y la destrucción asociada al sismo de Lima en el siglo XVIII; Mark Alan Healey estudió las relaciones entre Iglesia y Estado posteriores al terremoto de 1944 en San Juan, Argentina; Renée de la Torre expuso las teodiceas y sociodiceas asociadas a las explosiones de gas del 22 de abril de 1992 en Guadalajara, Jalisco, y Virginia García Acosta expuso los vínculos entre la historia y la antropología del riesgo y el desastre. Veáse: ROTH, 97 (2004): 11. 
apaches o nativos que bailan mostrando símbolos como las grecas, esculturas prehispánicas a Chac Mool e incluso atuendos burlescos y alusivos a los españoles como demonios. En el continente americano, las formas de comprender la naturaleza y sus manifestaciones conformaron en los indígenas una cosmovisión muy sólida que fue alterada en gran medida por los conquistadores y colonialistas, quienes «entre 1525 y 1540 realizaron una destrucción sistemática de la religión indígena ${ }^{21}$. Como lo plantea Nettel, se impuso violentamente una distinta forma de pensar el bien y el mal, la ritualidad y la herejía, la vida y la muerte, el cielo y la tierra, lo espiritual y lo natural. Y aunque se realizó una oposición sistemática, se impuso el esquema español por medio de la burocratización administrativa y de la ritualidad religiosa.

El nuevo modelo y la presencia española fueron para los indígenas una «era aterradora [y la] consecuencia fue la despoblación por las epidemias, fenómeno sin precedente en la historia indígena. Nuevos males: viruela, sarampión, fiebre tifoidea, consumieron a la población ${ }^{22}$, y la despoblación facilitó la imposición de la supremacía iberoamericana. En las Cartas de Relación, ordenadas por el gobierno español, se aplicó la primera encuesta de amplia escala en la Nueva España, y en las respuestas a las preguntas se hizo evidente que los ancianos respondieron que el origen de esos males era la «voluntad de Dios o los pecados de los antepasados» ${ }^{23}$. En tales respuestas se mostró una explicación ya occidentalizada e impuesta en el racionamiento indígena. Nettel documentó que existían también algunas respuestas de corte anticolonial. Los cristianos apartaron a los indios de sus antiguos dioses que les decían qué hacer cuando enfermaban y por esa razón los nativos creían que empezaron a morirse. Ante la trasgresión, los dioses enviaron enfermedades que ellos mismos curaban, pero no lo hicieron por la desatención recibida. La resistencia ideológica gradualmente cedió y dio paso a un largo proceso de adaptación que involucró modelos arquitectónicos, recursos alimenticios, normas y reglamentos administrativos, pero también una ritualidad particular para enfrentar las peores amenazas. Esa ritualidad que se ha documentado específicamente relacionada con desastres permite caracterizar un modelo

21. Véase: NeTTEL, 30/2 (1994): 167-176.

22. NETTEL, 1994: 173.

23. NeTTEL, 1994: 173.

Revista de Historia Moderna, n. 35 (2017) (pp. 116-148) | ISSN-e: 1989-9823 | ISSN: 0212-5862 
reactivo ante las amenazas y los desastres, que en conjunto configura una estrategia adaptativa simbólica con prácticas que integran una planeación estratégica, una frecuencia de corta y larga duración, y una amplia escala de diseminación de las prácticas vinculadas a la estrategia, como se leerá en los siguientes argumentos.

\section{Escala de amplia cobertura y diseminación}

El culto a los santos católicos es una práctica que forma parte de la estrategia simbólica para enfrentar amenazas naturales. Es un ritual muy antiguo y tiene sus raíces en la cuna del cristianismo, a partir del cual se ha propagado por todo el mundo por medio de los santos padres como San José, San Pedro, San Pablo, San Judas, entre otros que acompañaron a Jesucristo. Durante siglos se polemizó la invocación a los santos, la idolatría y se dudó de la efectividad de su intercesión, sin embargo, se propagaron hasta ser protectores de oficios, sitios, comunidades, pueblos, ciudades y naciones enteras, de ahí la dificultad para delimitar geográficamente su influencia.

El reconocimiento oficial a los patronazgos proviene del Concilio de Trento. Durante la sesión XXV, celebrada los días 3 y 4 de diciembre del año de 1563, se reafirmó la veneración a los santos y reliquias, y la diseminación de los santos por orden de los representantes de la religión católica, con las siguientes palabras:

Manda el santo Concilio a todos los Obispos, y demás personas que tienen el cargo y obligación de enseñar, que instruyan con exactitud a los fieles ante todas [las] cosas, sobre la intercesión e invocación de los santos, honor de las reliquias, y uso legítimo de las imágenes, según la costumbre de la Iglesia Católica y Apostólica, recibida desde los tiempos primitivos de la religión cristiana, y según el consentimiento de los santos Padres, y los decretos de los sagrados concilios; enseñándoles que los santos que reinan juntamente con Cristo, ruegan a Dios por los hombres; que es bueno y útil invocarlos humildemente, y recurrir a sus oraciones, intercesión, y auxilio para alcanzar de Dios los beneficios por Jesucristo su hijo, nuestro Señor, que es solo nuestro redentor y salvador; y que piensan impíamente los que niegan que se deben invocar los santos que gozan en el cielo de eterna felicidad; o los que afirman que los santos no ruegan por los hombres; o que es idolatría invocarlos, para que rueguen por nosotros, aun por cada uno en particular; o que repugna a la palabra de Dios, y se opone al honor de Jesucristo, único 
mediador entre Dios y los hombres; o que es necedad suplicar verbal o mentalmente a los que reinan en el cielo ${ }^{24}$.

Así, la mayor parte de los pueblos católicos reconocieron el carácter especial de ciertos seres que destacaron entre los demás por sus obras en beneficio de la religión católica y de su Dios. Cargaron a esos personajes de admiración y gratitud por sus actos, como sacrificar la vida por defender a Dios, servir a los más necesitados y enfrentar las peores amenazas, incluso a costa de su propia vida. Por tales méritos, la comunidad religiosa consideró que esos santos tenían la capacidad de intervenir en cualquier sitio para proteger a los individuos y los fieles. Se dedujo que esos personajes tan bienhechores se encontraban reinando con Cristo y que tenían la capacidad de implorar a Dios en nombre de la sociedad, y por lo tanto se les podía invocar en cualquier lugar donde fuera necesaria su intercesión ante Dios. Para reconocerlos les confirieron el rango de patrón, y por patronazgo se entiende el reconocimiento recibido, pero también el ejercicio de servir como intercesión ante ciertas circunstancias. De esa manera la Iglesia perpetuó la memoria de esos fieles, honró sus reliquias y los sepulcros en el mundo católico sin límites de escala.

Varios factores influyeron en la diseminación del modelo religioso como práctica para enfrentar amenazas naturales. Como señala Alberto Carrillo Cázares, en el siglo XVII se presentó en la Nueva España «una creciente tendencia a llamar a cada pueblo con el binomio en que se casan cielo y tierra para dar nombre y apellido a la estirpe de estos pueblos, donde no solo las personas, sino también las comunidades van quedando bautizados» ${ }^{25}$. Así, se realizó la conjunción de los santos de Castilla con las señas de la tierra: santo y seña, se creó una geografía sacralizada, según interpretación de Carrillo. ${ }^{26}$ De esta manera, los santos patronos, con su imagen piadosa o dolorosa en sus imágenes y esculturas, produjeron desde entonces una gran influencia como

24. Véase: Concilio de TREnTO, 1845.

25. CARrillo Cázares, 1993: 31.

26. Un caso representativo es Santiago Pinotepa Nacional, Guerrero, México, cuyo nombre proviene de Santiago Apóstol, un santo invocado por los españoles ante la escasez de lluvias y varios vocablos en náhuatl: pinolli, que significa casa desmoronada, tepetl, que es cerro y pan que significa hacia, y que conjugados forman la frase «hacia el cerro desmoronado». En Santiago Pinotepa se realizaban rogativas documentadas a principios del siglo Xx cada 24 y 25 de julio. 
elemento de cohesión social, un referente geográfico y un factor de beneficio para la Iglesia por las donaciones que se le confieren al santo.

En el siglo XVII en México se ordenó la creación de congregaciones. De acuerdo con Carrillo, los jueces comisionados obligaron a efectuar el movimiento poblacional con tal de agrupar comunidades y asentamientos familiares que se ubicaban dispersos. Por consecuencia, todos los indios por las buenas o por la fuerza tuvieron que dejar sus antiguos sitios para concentrarse «como barrios aledaños a sus cabeceras o como nuevos poblamientos de traza castellana, en torno a una plaza y a la sombra de un campanario ${ }^{27}$. Esta disposición fue perjudicial porque alteró las dinámicas de sobrevivencia que tenían los indígenas y afectó sus sistemas de cultivos, obligándolos a vivir congregados en sitios expuestos a amenazas naturales. Luego los españoles destruyeron los pueblos indígenas, derribaron los templos y sitios tradicionales ceremoniales, y algunas imágenes fueron trasladadas a los templos católicos para atraer a los nativos. El historiador Carrillo Cázares interpreta que entonces la Iglesia procedió a consolar a los trasterrados y cuidar los vecindarios, y como prenda de amparo les dio a cada uno (o les refrendó) el patrocinio de un santo, cuyo nombre fue enlazado al nombre primitivo del pueblo para que se le dotara de una condición casi sagrada, y para que el santo les animara a sobrevivir en el mapa de la geografía terrenal y en el plano de una cosmografía celestial.

Algunos santos lograron patrocinio universal como san Pedro, san Pablo y san José, y vírgenes como la Virgen de los Remedios, la Virgen de Guadalupe, la Candelaria, entre otras que para la población han brindado diversos beneficios ante amenazas naturales y por lo tanto han ganado aprecio en la Iglesia católica. De esta manera la protección simbólica de los patronazgos se ha diseminado por el mundo católico y está presente en cada espacio terrestre donde existe un agente natural potencialmente peligroso. Así, las condiciones meteorológicas están ligadas a la dispersión e invocación a ciertos santos patronos protectores de las amenazas más adversas que caracterizan al clima o subclima de cada área. Los rituales ancestrales suelen relacionarse con algún acontecimiento desastroso y por lo tanto los patronazgos son portadores de la memoria asociada a desastres. En poblaciones donde los desastres son

27. Carrillo Cázares, 1993: 31.

Revista de Historia Moderna, n. 35 (2017) (pp. 116-148) | ISSN-e: 1989-9823 | ISSN: 0212-5862 
frecuentes la sociedad les asigna un nombre relacionado con el santoral; por ejemplo, en el Caribe se recuerda el huracán de san Ciriaco y el huracán de san Zenón ${ }^{28}$. Estas expresiones religiosas vinculadas con un suceso desastroso han sido interpretadas como «estrategias adoptadas históricamente como una forma de incorporar los tiempos de grandes pérdidas en la memoria de la comunidad para volverlos más manejables en una escala de humanidad individual ${ }^{29}$.

Con los patronazgos se transmite lo bueno y lo malo, como es el caso de el Cordonazo, cuyo nombre advierte la presencia de un peligro. Su origen y causas se remontan al pasado y es complejo documentar su diseminación. El caso de san Francisco de Asís, patrono contra tempestades, es ejemplar para ilustrar la devoción más allá de la efectividad protectora del santo ${ }^{30}$. San Francisco de Asís ha enfrentado huracanes y otras tempestades con una frecuencia anual durante siglos y aunque han ocurrido múltiples desastres, su patronazgo se ha diseminado por las ciudades, pueblos y países del mundo católico, por ejemplo, México, Cuba y Filipinas, donde la incidencia de impactos por ciclones tropicales es superior a la media internacional. En Filipinas los desastres asociados a huracanes y otras amenazas son tan frecuentes que la sociedad ha desarrollado una «cultura de desastres», definida por el historiador Greg Bankoff, es decir, un conjunto de manifestaciones culturales y religiosas asociadas a los desastres ${ }^{31}$. Incluso en estos países, san Francisco de Asís tiene una ambivalencia, ya que se le considera protector de tempestades, pero también se tiene por peligroso el día 4 de octubre, día que se conmemora su muerte y se cree que el santo flagela con su cordón a los pecadores enviando un huracán muy potente. Así, el 4 de octubre puede presentarse el Cordonazo de san Francisco, un huracán poderoso como los documentados en Filipinas los días 4 de octubre de los años 1596 y 1881, en México en la península de Baja California Sur en el año de 1958, y en Cuba en el año 2016 ante el huracán Matthew, categoría 4. La coincidencia es lógica porque en las tres regiones tropicales el mes de octubre presenta

28. SCHWARTZ, 83/4 (2005): 382.

29. BANKOFF, 2003: 169.

30. Véase: VAUCHEZ, 2012.

31. Véase: BANKOFF, 2003.

Revista de Historia Moderna, n. ${ }^{\circ} 35$ (2017) (pp. 116-148) | ISSN-e: 1989-9823 | ISSN: 0212-5862 
condiciones para el incremento de estos fenómenos extremos, y para los devotos, todo huracán que ocurra en cualquier día de octubre puede tratarse de un Cordonazo.

A mediados del siglo Xx, el antropólogo español Fernando Ortiz, durante sus investigaciones en el Caribe, documentó que los antillanos llamaban Cordonazo de San Francisco a ciertos huracanes,

imaginando que sus ráfagas eran debidas a un ser celestial que los zurriagaba desde lo alto [...] y la circunstancia de llevar el pobre santo asisiano un nudoso cordón atado a la cintura sobre su sayal, hicieron que la incultura atribuyera impíamente aquellas desapoderadas iras de los huracanes antillanos a la cólera del humildísimo fraile ${ }^{32}$.

Al parecer el Cordonazo de san Francisco pudo llegar a las poblaciones asentadas en el litoral mexicano, frente al océano Pacífico, hace más de cuatro siglos en las naves que viajaron entre México y Filipinas, haciendo escalas en distintos puertos durante el tornaviaje ${ }^{33}$. En 1913, el meteorólogo Willis E. Hurd publicó que en Baja California Sur las «tormentas más intensas son esperadas, especialmente hacia el final de la temporada, cerca o después del día de fiesta de San Francisco, en octubre, cuando la población de la costa oeste busca el cordonazo» ${ }^{34}$. Este huracán, según Hurd, «no solamente ha causado estragos a los botes de los pescadores, sino también ha destruido sus casas, por ello algunas villas temen y quedan desiertas durante los meses de amenaza $»^{35}$. Dos años después, otro meteorólogo norteamericano que indagaba los antecedentes de ciclones tropicales en el océano Pacífico también encontró alusiones a el Cordonazo:

al este de las islas de Hawai se encuentra la región del cordonazo de San Francisco, el imaginario nombre dado por los españoles a los violentos vientos que ocurren en la costa oeste de México, uno en cada siete u ocho años, hacia el cierre de la temporada de lluvias; esto es, cerca del tiempo del Día de San Francisco, octubre $4^{36}$.

32. ORTIZ, 1947: 76-77.

33. Véase: MACHUCA, y CALVO (coords.), 2016.

34. HURD, 57/2 (1929): 44.

35. HURD, 57/2 (1929): 44.

36. KIMBALL, 43 (1915): 486. 
En la península mexicana de Baja California Sur se creía que san Francisco flagelaba con el cordón a los pecadores durante cualquier huracán de octubre. Por ejemplo, en San José del Cabo y La Paz el 26 de octubre de 1857 se presentó un huracán, «el cual destruyó 37 casas y causó la muerte de algunos vecinos, sin precisión en la cifra, fue llamado cordonazo de San Francisco». ${ }^{37}$

En el occidente de México también se conoce el Cordonazo de san Francisco. El primer registro asociado a el Cordonazo data de un huracán en el año de 1870, cuyos efectos produjeron el 4 de octubre el hundimiento del buque norteamericano Puertas de Oro. Otro Cordonazo el 4 de octubre de 1942 ocasionó abundantes inundaciones en el estado de Colima y en la ciudad de Cihuatlán, Jalisco. Y uno más en 1950 transportó vientos intensos e inundaciones en diversas poblaciones ${ }^{38}$. Esta coincidencia ocurre por la alta incidencia de huracanes en dicho mes, aunque estadísticamente los meses más activos en el océano Pacífico han sido agosto y septiembre, pero octubre aporta una gran cuota. Según estudios históricos de huracanes, entre 1527 y 1899 se reportaron en Colima, en el mes de octubre, trece eventos con características de huracanes; entre 1900 y 1999 se han registrado veintiocho solo en el mes de octubre; y entre los años 2000 y el 2013 un total de seis muy intensos ${ }^{39}$. Por lo anterior, a través de la historia se han documentado coincidencias de huracanes percibidos el día 4 del mes de octubre; sin embargo, la actividad ciclónica es abundante todo el mes y es posible que la población asocie esos huracanes cercanos a las fechas para justificar el Cordonazo. En síntesis, el caso de el Cordonazo de san Francisco aporta evidencia para mostrar la amplia escala de influencia de las creencias españolas en las sociedades mexicanas en distintas épocas en que se han presentado ciclones tropicales.

\section{Planeación estratégica y ejecución}

El procedimiento de la Inquisición, iniciado en el siglo XII, perduró por varios siglos de manera sistemática, pero su modelo se ejecutó esporádicamente en los siglos posteriores. La Iglesia desarrolló desde el siglo XVI complejos documentos para reprobar las supersticiones y hechicerías, como el manual

37. ESCOBAR OHMSTEDE, 2004: 84.

38. PAdilla LOZOYA, 2014a: 291.

39. Ibid.

Revista de Historia Moderna, n. ${ }^{\circ} 35$ (2017) (pp. 116-148) | ISSN-e: 1989-9823 | ISSN: 0212-5862 
Reprobación de las supersticiones... multi-editado y divulgado por el mundo católico $^{40}$. Con este tipo de teoría alimentaron su intelecto los representantes de la Iglesia, conquistadores, colonizadores y funcionarios que cruzaron el Atlántico en los siglos XV y XVI para imponer a los nativos un nuevo modelo de pensamiento y para dar forma a lo que ellos veían como sociedad novohispana desordenada, mediante un estratégico procedimiento ideológico de larga duración ${ }^{41}$. En los siglos XV, XVI y XVII, tanto en España como en México, las prácticas no autorizadas por la Iglesia que intentaban controlar las manifestaciones naturales eran consideradas nigromancia, brujería o hechicería, y el castigo por practicarlas era fatal. Por ejemplo, durante las prolongadas inundaciones de 1817 y 1818 en Cataluña, fueron ejecutadas cerca de 400 mujeres acusadas de brujería y de causar los desastres ocurridos. ${ }^{42}$

Algunos líderes de las sociedades española y novohispana anteriores al siglo XIX contaban con limitadas capacidades para comprender la física de los fenómenos naturales y procuraban explicar los eventos por intervención divina. En México la población era sumamente temerosa de todo lo extraño, de lo poco frecuente, de lo nunca visto, de lo impredecible, de lo cósmico y hasta de la noche. En su sistema analítico de la realidad se interponía una explicación espiritual o paranormal antes que aplicar cualquier comprobación técnica. La sociedad novohispana disponía de un marco acotado de actuación y reflexividad porque durante siglos las autoridades eclesiásticas y civiles impusieron las normas de conducta social, las formas de comprender lo cultural, lo científico, lo bueno y malo, y lo divino. La Iglesia católica promovió la comprensión de la naturaleza como un elemento impredecible y controlable solamente por Dios, y por una corte celestial de santos y vírgenes. El clero consideraba al desastre como un evento inevitable ante la

40. Véase: DE Burgos, (ed.), 1547.

41. La estrategia y la práctica constituyen un debate actual e interdisciplinario, debido a que en ciertos estudios se usan como sinónimos, pero no lo son. Por ello, en el presente estudio se analizan las prácticas rituales contra amenazas y desastres como parte de una estrategia adaptativa que incluye tres elementos imprescindibles de un procedimiento estratégico: un plan, frecuencia y escala. De esta manera, se introduce al debate de las estrategias adaptativas la dimensión espiritual o religiosa utilizada para proteger simbólicamente a las sociedades españolas y mexicanas, modernas y contemporáneas, de las cuales aún perduran sus componentes esenciales.

42. PÉREZ SAMPER, 2009: 139. 
ira de Dios debido a los pecados cometidos. El castigo tenía el propósito de sancionar, pero también de mejorar la condición espiritual de cada creyente por medio de su arrepentimiento ante la destrucción purificadora causada por los elementos naturales. La Iglesia en contubernio con el Estado se constituyeron en las instituciones con la autoridad y el poder para enfrentar lo que causaba miedo y desgracia a la población desprotegida y más creyente, así como para castigar el satanismo y también aquello que desde su criterio atentara contra su manera de comprender las causas de los eventos naturales y desastres.

La estrategia ideológica que establecieron la Iglesia y el gobierno para enfrentar las amenazas naturales estaba enfocada en controlar el desánimo por medio de la fe. Por ello brindaban apoyo espiritual a las víctimas del desastre y les inducían a congraciarse con Dios, agradeciendo su bendición por la vida y esforzándose en reconstruir el patrimonio. Sin embargo, omitían identificar las causas del desastre en los factores de exposición a la amenaza, excluían del discurso el inadecuado sistema constructivo y las limitadas capacidades preparativas y preventivas. En su perspectiva siempre era exógena la amenaza que causaba el desastre y poco podía hacerse ante un elemento que estaba fuera del control de los humanos, por ello, la única defensa era utilizar medios divinos como mostrar fervor religioso y público deseo de arrepentimiento. Entonces se planeó realizar ciertas prácticas rituales públicas que han sido documentadas, como las rogativas y procesiones, las prácticas rituales populares que efectuaba la sociedad productiva para sembrar semillas y enfrentar la crisis alimenticia, rehabilitar sus condiciones elementales y reconstruir en la medida de lo posible el patrimonio y los bienes perdidos ${ }^{43}$. De esta manera, las autoridades depositaron en el santo patrono la responsabilidad de enfrentar a la amenaza y la culpa del desastre a Dios. La naturaleza era la justiciera, pero Dios daba la orden de ajusticiar o castigar.

Para fines analíticos es válido agrupar las prácticas que desarrollaban tanto las élites tomadoras de decisiones, como la sociedad civil con menos recursos económicos, pero con gran ingenio, para paliar los daños y aprovechar el capital social para dar continuidad a su desarrollo. El modelo ritual

43. Véase: Molina del Villar, 1996. Alberola Romá, 21 (2003); 23 (2005). Franco Rubio, 2009. Pérez Samper, 2009. Alberola Romá, y Olcina (eds.), 2009. 
español que se implementó para enfrentar a las amenazas fue inadecuado para evitar los desastres, por ello fueron frecuentes los eventos desastrosos en España durante los siglos XV al XVIII; sin embargo, ese modelo litúrgico pasó a Hispanoamérica con similitudes fundamentales. En el continente americano los virreyes y demás autoridades participaban de manera conjunta con los máximos representantes del clero. Por medio de funcionarios especiales se organizaban las rogativas, procesiones y otros rituales. Los procuradores solicitaban la ejecución del ritual y esta propuesta requería de oficialización por medio del visto bueno de ambos poderes ${ }^{44}$. De esta manera, la petición, gestión burocrática del trámite, gastos, ejecución y evaluación de resultados, constituía en conjunto una planeación que ha quedado documentada a detalle sobre cómo realizar las rogativas y procesiones; quiénes participan en ellas, en qué orden se realiza el recorrido, qué trayectoria, en qué sitios, con qué frecuencia se ofician las misas, qué manifestaciones devotas son permitidas y cómo sancionar a quienes infringen los reglamentos, alteren el orden o deshonren al santo ${ }^{45}$. En las grandes ciudades hispanoamericanas era muy similar la estructura burocrática que tomaba decisiones, mientras que en las pequeñas ciudades y pueblos el tema aún tenía lagunas importantes. El costo era importante para magnificar el evento y proyectar su teatralidad, y no siempre se contaba con recursos suficientes del erario para financiar las rogativas, sobre todo cuando se había padecido un desastre de grandes proporciones, por ello debía invertirse el dinero de manera regulada, y en los pueblos las rogativas eran menos masivas y espectaculares.

La planeación estratégica que realizaron la Iglesia y el Estado tuvo como objetivo una amplia cobertura, y consistió en integrar a ambas instituciones para involucrar a toda la sociedad en las prácticas requeridas. De esta manera se compartió el apoyo a la población con cierto paternalismo al suministrar auxilio médico, apoyos como vestimenta, y ayudas como pan a los afectados, pero entre ambos crearon argumentos en su beneficio. Por un lado, la Iglesia culpaba del desastre a la ira de Dios por los pecados cometidos por el pueblo

44. Alberola Romá, 2009: 20.

45. Las respuestas religiosas en la Ciudad de México son un extraordinario ejemplo del modelo que se implementó en las grandes ciudades hispanoamericanas y el aporte de la historiadora América Molina del Villar es imprescindible para comprender la logística. Véase MOLINA DEL VILLAR, 1996. 
y ofrecía el camino de la salvación; y por el otro, el Estado se fortalecía como el benefactor del pueblo sometido y concentrado en paliar sus culpas para evitar más castigo. En la ejecución del plan, los culpables de los desastres no eran los religiosos ni las decisiones de los líderes novohispanos por asentar poblados en zonas expuestas ante amenazas naturales, como los cauces de ríos, valles inundables y pueblos y puertos costeros en peligro por huracanes. Así se evitaron los reclamos sociales por malas decisiones, se controló el éxodo y las migraciones constantes o nomadismo.

Para América Molina la respuesta civil y religiosa, tan reglamentada ante los desastres, sirvió como mecanismo para mantener el control sobre la sociedad. Toda incorporación al ritual debía ser aprobada por el clero y el comité organizador. De manera similar, Gloria A. Franco nota que en España estas medidas tan ordenadas, burocratizadas, oficializadas y obligatorias, sirvieron a la Iglesia y al Estado

para mantener sometida a la población mediante un férreo control ideológico que, ejercido de forma conjunta, siempre favorecía sus intereses tanto a corto como a medio y largo plazo, ya que con ellos se evitaba alteraciones sociales y episodios de inseguridad que podían poner el peligro el sistema vigente ${ }^{46}$.

En el modelo planeado y ejecutado por la Iglesia y el Estado, de manera conjunta convinieron en que la única protección y salvación vendría de la corte celestial. Si Dios ordenaba los castigos, era necesario incorporar intercesores para aplacar su ira, y los más capaces de interceder ante Dios eran los santos, vírgenes, y ángeles como san Miguel Arcángel, y en ocasiones se incluían objetos religiosos como el santo crucifijo y las reliquias de los mártires, beatos, y santos. Así, las rogativas y procesiones eran para pedir el favor a las divinidades, y para conmover a los intercesores fueron incorporados elementos que evidenciaran el fervor, el arrepentimiento y el deseo de ser perdonado para seguir viviendo y mejorar como siervo de Dios. Durante las procesiones de rogativas, sobre todo en las grandes ciudades, participaban voluntarios, autoridades civiles y religiosas, pero sobre todo los sacerdotes, quienes portaban un hábito color oscuro y los elementos que consideraban convenientes; podían elegir «los instrumentos que Dios les inspirara ${ }^{47}$ como castigo, ya

46. FRANCO RUBIO, 2009: 215.

47. GARCÍA TORRES, 2013: 113.

Revista de Historia Moderna, n. ${ }^{\circ} 35$ (2017) (pp. 116-148) | ISSN-e: 1989-9823 | ISSN: 0212-5862 
fuera látigos, ganchos, cadenas o el cilicio. Acostumbraban a caminar descalzos, algunos colocaban coronas de espinas en la cabeza, cadenas al cuello, rocas colgadas con sogas, huesos en la boca, calaveras en las manos, se cubrían el cuerpo de ceniza como símbolo de contrición y cargaban pesadas cruces de madera para expiar pecados y mostrar sumisión ante el castigo divino ${ }^{48}$. En el ambiente se respiraba el olor de la cera de veladoras, la sangre y se creaba un escenario de lamentación muy dramático, acompañado de campanadas, sonido de golpes, lamentos, rezos y llantos. Todo en conjunto convencía a los vecinos de que serían escuchados y atendidas sus súplicas. Sin embargo, cuando no se recibía la respuesta adecuada se insistía con más procesiones y romerías. La recurrencia no alteraba el modelo ni la planificación de estas prácticas de protección simbólica. Fueron prácticas simbólicas porque no se protegía a la sociedad materialmente ante la lluvia, la inundación, los rayos, granizos o sequías, pero el ritual producía la percepción de que estaban protegidos; en la antropología esta conducta social ha sido definida como inmunidad subjetiva ${ }^{49}$.

\section{Frecuencia en las prácticas}

La estrategia simbólica estaba conformada por prácticas que requerían cierta frecuencia. En el mundo católico la frecuencia era importante para transferir la ritualidad, y el ejercicio constante propiciaba la disciplina de los fieles. Se rezaba todos los días y en el caso de México durante siglos se rezó en cada familia el Santo Rosario y además alguna oración al santo patrono, todos los días, por la noche o en el día. Así, diariamente se recordaba e imploraba a los santos patronos que protegían a la población de la falta de alimentos, las inclemencias meteorológicas o las enfermedades. De esta manera y por medio de tradición oral, la población española y mexicana trasmitió rezos, conjuros y ensalmos de sacerdotes a padres e hijos, aunque solían presentarse modificaciones durante el proceso.

En México y en España se efectuaban rogativas cada vez que se presentaba una amenaza, como una escasez de lluvia o una sequía, pero también cuando ocurría un desastre asociado a una inundación, ciclón tropical u otra

48. GARCÍA TORRES, 2013: 113.

49. Véase: DougLAS, 1996.

Revista de Historia Moderna, n. ${ }^{\circ} 35$ (2017) (pp. 116-148) | ISSN-e: 1989-9823 | ISSN: 0212-5862 
manifestación meteorológica. La frecuencia se instauró al oficializarse los calendarios de santos cristianos como el Martyrologium romanum de 1586 o el santoral, el cual permitió programar anualmente las conmemoraciones a los santos; uno o más por cada día ${ }^{50}$. El número de santos incrementó gradualmente desde la Edad Media, pero con el Concilio de Trento de 1563 se autorizó a los sacerdotes y obispos a nombrar santos patronos en cada diócesis, pueblo o parroquia ${ }^{51}$. En México, desde el siglo XVI se incorporaron también las fiestas en honor a los santos patronos, acompañadas de convites con música, alimentos y fuegos pirotécnicos, como lo han documentado diversas investigaciones. Las conmemoraciones anuales devenían en festividad, en cambio las rogativas y procesiones ante una amenaza o durante un desastre estaban revestidas por la institucionalidad y ritualidad católica más formal y atribulada.

Los patronazgos en cada pueblo o ciudad podían prolongarse por siglos, con celebraciones anuales, juramento al santo y renovación del mismo, sobre todo después de un evento desastroso. En otros casos el patronazgo duraba un breve período si no se recibían los favores solicitados y entonces se buscaba la intercesión de algún otro santo incluido en el santoral. Por ejemplo, en 1723 en Alicante, España, los vecinos cambiaron a san Roque y san Pedro por el Cristo del Calvario, porque no recibieron de ambos los favores que solicitaban para mitigar la sequía que los aquejaba ${ }^{52}$.

En el contexto virreinal mexicano se incorporó la religiosidad en la vida diaria y en los métodos de producción. Algunos santos perduraron porque se les adjudicó una habilidad particular contra una amenaza que atentaba contra las siembras y cosechas. Así hubo santos especializados en proteger ante algunos peligros, por ejemplo, san Isidro Labrador, santo protector del buen temporal, a quien se le solicitaba apoyo tanto por escasez de lluvia como por inundaciones, para lograr buenas cosechas. Entre las vírgenes más adoradas en la Ciudad de México, «la Virgen de los Remedios se invocaba por la falta de lluvias, mientras la de Guadalupe era la protectora contra las

50. Véase: BARONIO, 1586.

51. Se estima que actualmente el número de santos rebasa los diez mil, pero no hay una cifra precisa y oficial.

52. García TORRES, 2013: 106.

Revista de Historia Moderna, n. ${ }^{\circ} 35$ (2017) (pp. 116-148) | ISSN-e: 1989-9823 | ISSN: 0212-5862 
inundaciones, y la de la Bala se invocaba contra alguna enfermedad. Cada advocación contaba con un culto especial, festividades, cofradías, novenas, traídas y peregrinaciones, así como autoridades civiles, eclesiásticas y órdenes religiosas que fomentaban el culto a una o varias advocaciones $\rangle^{53}$.

El número incalculable de santos patronos y la variable frecuencia de sus conmemoraciones los convierte en un objeto de investigación complejo para caracterizarlos. Existen varios santos patronos para cada tipo de amenaza como las lluvias, tempestades, huracanes, granizadas, heladas, sequías, inundaciones, rayos, centellas, enfermedades epidémicas y plagas de gusanos, langostas y amenazas geológicas como los tsunamis, erupciones volcánicas y sismos. También se ha documentado una innumerable cantidad de santos contra amenazas antropogénicas, como guerras, incendios, accidentes aéreos, incidentes navales, y otros para los oficios, algunos de ellos contenidos en el santoral y en publicaciones especializadas ${ }^{54}$. Además, varios santos pueden ser utilizados contra el mismo tipo de manifestación natural, ya sea en distintos pueblos o incluso en el mismo. Por ejemplo, durante la inundación que inició el 12 de septiembre de 1629 y duró cinco años en la Ciudad de México, se solicitó por medio de rogativas la intervención de san Gregorio, la Virgen de los Remedios, la Virgen de Guadalupe y santa Catarina ante la misma amenaza. En todos los casos la respuesta fue negativa, la inundación continuó y la amenaza se presentó anualmente con distinta escala hasta nuestros días. El problema de la Ciudad de México es que se encuentra ubicada en un valle inundable y ningún santo podrá evitar que se inunde. Sin embargo, con algunos santos patronos la devoción se ha perpetuado y las procesiones y rogativas se han realizado anualmente o con cierta regularidad a pesar de que la manifestación natural detone desastres frecuentemente. Durante siglos, la estrategia adaptativa simbólica ha vinculado a los creyentes con lo divino, pero las causas de base de los desastres son sociales y se encuentran

53. MATABUENA, y RodRíGUEZ, 2008: 43-45.

54. Véase: MRS. JAMESON, 1857. Agradezco al Museo Franz Mayer de la Ciudad de México la consulta del ejemplar en que se describe la ficha biográfica y las leyendas milagrosas de los santos patronos de Christendom, las vírgenes patronas, los primeros mártires, los mártires griegos, los mártires latinos, los mártires romanos, los mártires de Tuscania, Lombardía, España y Francia, los primeros sacerdotes santificados y las ermitas de los santos. 
profundamente enraizadas en los factores socioeconómicos que han vulnerado históricamente a las sociedades más expuestas, menos preparadas y desprevenidas.

\section{Conclusiones}

La respuesta ante fenómenos naturales amenazantes y desastres por medio de la protección simbólica y de la intervención de los denominados santos patronos ha sido un elemento fundamental de la ritualidad cristiana. La evidencia histórica muestra que el modelo de protección simbólica ha perdurado por siglos al ser parte del proceso adaptativo de las sociedades ante las amenazas y los desastres. A los ajustes ecológicos, económicos, políticos y sociales, la sociedad ha incorporado diversas prácticas culturales como parte del proceso adaptativo, y dentro de esa dimensión cultural se ubica la protección simbólica que permite cierta cohesión social para enfrentar las tragedias que ponen en riesgo al sistema de gobierno y al ideológico-religioso.

El estudio de la adaptación debe incorporar a la religiosidad y a la noción de protección simbólica porque son elementos prácticos que inciden en la estrategia adaptativa simbólica desarrollada para enfrentar las amenazas naturales y los desastres. Este modelo estratégico sigue vigente y aún se producen procesiones masivas en países como España, México y Filipinas, y de tamaño variable en los pueblos donde se cuenta con un santo patrono que se conmemora anualmente o después de una tragedia.

A pesar del fortalecimiento a la instrumentación que se impulsó desde el siglo XVI para reconocer la física de los fenómenos hidrometeorológicos, las manifestaciones religiosas como las rogativas a santos patronos se han perpetuado por siglos en el mundo católico y funcionan como mecanismo simbólico de protección. Aún en nuestros días, millones de devotos comprenden a los desastres del mismo modo que en el siglo XVIII, cuando se creía que eran voluntad de Dios, resultado de castigos divinos por pecados cometidos o un bien para purificar la sociedad y encaminarla por el buen sendero.

Como lo precisa David Alexander en la obra de David Etkin, los desastres deben comprenderse también como eventos simbólicos, ya que la población asigna a estos acontecimientos un significado. La noción de que la tragedia carece de sentido es aborrecible para la mayoría de la gente y por eso nos 
damos cuenta de cómo entenderla en términos de Dios, la moralidad, la justicia o las lecciones de la vida. Simbólicamente, los desastres pueden ser hitos en la vida o en la comunidad, metáfora, alegoría o parábola, pueden «demostrar gráficamente la aparente arbitrariedad del destino», o pueden ser un recordatorio de la presencia fugaz de la vida y nuestra mortalidad $»^{55}$.

Los desastres tensan las relaciones sociales y muestran lo mejor y lo peor de la sociedad. Así, las procesiones por rogativas al santo patrono fortalecieron la resiliencia por medio de la identidad grupal, pero también mostraron que a pesar de la tragedia y el humanismo que entraña la fe católica, la estructura del ritual mantenía una jerarquización evidente en el orden, autorización y función de cada participante. La procesión muestra el orden auto establecido por las élites religiosas y civiles, hasta los más desamparados.

En la actualidad aún son nombrados santos patronos contra amenazas naturales, como lo ejemplifican en México el Cristo de los brazos caídos en Barra de Navidad, Jalisco; santa María del Mar en Cuyutlán, Colima; la Virgen de la Puntilla en Sinaloa y san Lucas en Baja California Sur, por mencionar algunos que protegen simbólicamente contra las inclemencias meteorológicas. Esto parece ocurrir porque a pesar de la estrategia nacional de protección civil, la sociedad sigue confiando en la protección divina, sin importar que su escala de funcionamiento sea la simbólica. Se consolida así su ideología, por medio del capital social que ayuda a las sociedades religiosas a mitigar los daños, paliar las necesidades, enfrentar la trágica realidad y que les permite con ciertas prácticas, integrar una estrategia adaptativa de larga duración, que debe ser comprendida a detalle por quienes planean intervenir a una comunidad con el propósito de reducir los riesgos y prevenir desastres.

\section{Bibliografía}

Alberola RomÁ, Armando, «Procesiones, rogativas, conjuros y exorcismos: el campo valenciano ante la plaga de langosta de 1756», Revista de historia moderna, 21 (2003): 383-410. http://dx.doi.org/10.14198/RHM2003.21.17

Alberola Romá, Armando (coord.), «Agricultura, riesgos naturales y crisis en la España Moderna», Revista de Historia Moderna: Anales de la Universidad de Alicante, 23 (2005). Disponible en: http://rua.ua.es/dspace/handle/10045/4618

55. ETKIN, 2016: 258.

Revista de Historia Moderna, n. 35 (2017) (pp. 116-148) | ISSN-e: 1989-9823 | ISSN: 0212-5862 
Alberola RomÁ, Armando, «La naturaleza desatada: manuscritos, impresos e imágenes sobre desastres naturales en la España del siglo XVIII», en Armando Alberola Romá y Jorge Olcina (eds.), Desastre natural, vida cotidiana y religiosidad popular en la España moderna y contemporánea, Alicante, Universidad de Alicante, 2009: 17-76.

AlbORES, Beatriz y BRODA, Johanna (coords.), Graniceros, cosmovisión meteorología indígena de Mesoamérica, México: El Colegio Mexiquense A.C. e Instituto de Investigaciones Históricas, UNAM, 2003.

Arrioja, Luis Alberto y Alberola, Armando (eds.), Clima, desastres y convulsiones sociales en España e Hispanoamérica, siglos XVII-XX, Alicante, Universidad de Alicante/El Colegio de Michoacán, 2016.

BANKOFF, Greg, Cultures of disaster, society and natural hazard in the Philippines, London/ New York, Routledge Curzon, 2003.

BARONIO, Cesare, Martyrologium romanum: ad nouam kalendari rationem, Gregorii XIII Pont, Roma, Romae ex Typographia Dominici Basae, 1586.

BENNETT, John W., The ecological transition, Exeter, A. Wheaton \& Co., 1976.

BuRgos, Andrés de (ed.), Reprobación de las supersticiones y hechicerías libro muy útil y necesario a todos los buenos cristianos el cual compuso y escribió el maestro Pedro Ciruelo y ahora de nuevo lo ha revisto y corregido, y aún le ha añadido algunas mejorías, con sus acotaciones por las márgenes, Sevilla, Casa de Andrés de Burgos, 1547, Disponible en: http://bdh-rd.bne.es/viewer.vm?i$\mathrm{d}=0000115521$ \&page $=1$ [consultado el 22 de diciembre de 2016]

Carrillo CÁZares, Alberto, Michoacán en el otoño del siglo XVII, Zamora, El Colegio de Michoacán/Gobierno del Estado de Michoacán, 1993.

Claxton, Robert H. (ed.), «Investigating natural hazards in Latin American history», Studies in the Social Sciences, XXV (1986): 1-167.

Concilio de Trento, El Sacrosanto y ecuménico Concilio de Trento, Barcelona, Imprenta de Benito Espona, 1845. Disponible en: http://bdh-rd.bne.es/viewer. vm?id=0000131359\&page $=1$ [consultado el 20 de diciembre de 2016]

Douglas, Mary, La aceptabilidad del riesgo según las ciencias sociales, Barcelona, Paidos, 1996.

Dynes, Rusell, Marchi, Bruna de y Pelanda, Carlo (eds.), Sociology of Disasters. Contribution of sociology to disaster research, Milán, Franco Agneli Libri, 1990. Escobar Ohmstede, Antonio, Desastres agrícolas en México. Catálogo histórico. Siglo XIX (1822-1900), tomo II, Ciudad de México, CIESAS-FCE, 2004. 
ETKIN, David, Disaster theory, an interdisciplinary approach to concepts and causes, Amsterdam, Elsevier, Butterworth-Heinemann, 2016.

FIRTH, Raymond, Social change in Tikopia. Re-study of a Polynesian community after a generation, Nueva York, The Macmillan Company, 1959.

FULTON, Elaine, «Acts of God: The confessionalization of disaster in Reformation Europe», en Andrea Janku, Gerrit J. Sckenk y Franz Mauelshagen (eds.), Historical disasters in context, science, religion and politics, Londres, Routledge, 2012: 54-74.

FRANCO RUBIO, Gloria A., «La fragilidad de la vida cotidiana en la España moderna», en Armando Alberola Romá y Jorge Olcina (eds.), Desastre natural, vida cotidiana y religiosidad popular en la España moderna y contemporánea, Alicante, Universidad de Alicante, 2009: 209-251. Disponible en: https:// https://www.ucm.es/data/cont/docs/995-2015-01-09-La\%20fragilidad\%20 de\%20la\%20vida\%20cotidiana.pdf

GASCÓN, Margarita, Percepción del desastre natural, Buenos Aires, Editorial Biblos, 2005.

García-Acosta, Virginia, Los sismos en la historia de México. Tomo II: El análisis social, México, Fondo de Cultura Económica, 2001.

GARCíA-AcostA, Virginia, «Historical disaster research», en Susanna M. Hoffman y Anthony Oliver-Smith (eds.), Catastrophe \& Culture. The Anthropology of Disaster, Santa Fe, School of American Research Press, 2002: 49-66.

GARCÍA TORRES, Adrián, "Víctimas del miedo: culpabilidad y auxilio del cielo frente a la catástrofe», en Armando Alberola Romá (coord.), Clima, naturaleza y desastre, España e Hispanoamérica durante la Edad Moderna, Valencia, Universidad de Valencia, 2013: 99-116.

Goloubinoff, Mariana, Katz, Esther y Lammel, Annamaría (eds.), Antropología del clima en el mundo hispanoamericano, T. I y II, Quito, Ediciones Abya-Yala, 1997.

GLOCKNer, Julio, Los volcanes sagrados, mitos y rituales en el Popocatépetl y la Iztaccíhuatl, México, Grijalbo, 1996.

Glockner, Julio, Así en el cielo como en la tierra, pedidores de lluvia del volcán, Ciudad de México, Benemérita Universidad de Puebla/ Grijalbo, 2000.

HURD, Willis Edwin, «Tropical cyclones of the eastern north pacific ocean», Monthly Weather Review, 57/2 (1929): 43-49. http://dx.doi. org/10.1175/1520-0493(1929)57\%3C43:TCOTEN\%3E2.0.CO;2 
JAMESOn, Mrs. [Anna], Sacred y legendary art. Vol. II: The patron saints, the martyrs, the early bishops, the hermits, and the warrior saints of christendom, as represented in the fine arts, Londres, Longman, 1857. Disponible en https:// books.google.es

Kimball, James, H. "A pacific hurricane of september, 1915», Monthly Weather Review 43(1915): 486. http://dx.doi. org/10.1175/1520-0493(1915)43\%3C486:APHOS\%3E2.0.CO;2

KRÜGER, Fred, et.al. (eds.), Cultures and Disasters: Understanding cultural framings in disaster risk reduction, Londres, Routledge, 2015.

Lammel, Annamária, Goloubinoff, Marina y Katz, Esther (eds.), Aires y lluvias. Antropología del clima en México, Ciudad de México, CIESAS/Centro de Estudios Mexicanos y Centroamericanos, 2008.

LeÓn-Portilla, Miguel, La visión de los vencidos, Ciudad de México, UNAM, 1992.

LERA DE ISLA, Ángel, «Rogativas para pedir la lluvia», Revista de Folklore, 3/29 (1983): 156-158. Disponible en Biblioteca Virtual Miguel de Cervantes. Disponible en: http://www.cervantesvirtual.com/obra/rogativas-para-pedir-la-lluvia/

LORENTE Y FERNÁNDEZ, David, La razzia cósmica: una concepción nahua sobre el clima. Deidades del agua y graniceros en la Sierra de Texcoco, México, CIESAS/ Universidad Iberoamericana, 2011.

Lowe, D. J., Newnham, R. M. y MCCraw, J. D., «Volcanism and early Maori society in New Zealand», en Robin Torrence y John Grattan (eds.), Natural disasters and cultural change, Londres/Nueva York, Routledge, 2002: 126161. Disponible en: https://www.researchgate.net/publication/240365695_ Volcanism_and_early_Maori_society_in_New_Zealand

Machuca, Paulina y CALvo, Thomas (coords.), México y Filipinas: cuatro siglos de historia compartida, México, Colegio de Michoacán, 2016.

Matabuena Peláez, Teresa y Rodríguez Lobato, Marisela, La milagrosa invención de un tesoro escondido..., México, Universidad Iberoamericana, 2008.

MCFADGEN, Bruce, Hostile shores, catastrophic events in prehistoric New Zealand and their impact on Maori coastal communities, Auckland, Auckland University Press, 2007.

Molina Del Villar, América, Por voluntad divina: escasez, epidemias y otras calamidades en la Ciudad de México, 1700-1762, Ciudad de México, CIESAS/SEP, 1996. 
NetTel, Patricia, «La colonización de lo imaginario, una historia cultural sobre México», en Mélanges de la Casa de Velázquez, 30/2 (1994):167-176. http:// dx.doi.org/10.3406/casa.1994.2706

Olivera, Carme, et. al., Los terremotos del año 1373 en los Pirineos: efectos en España y Francia, Barcelona: Generalidad de Cataluña, 1994.

Oliver-Smith, Anthony y Hoffman, Susanna M., (eds.), The Angry Earth. Disaster in Anthropological Perspective, Nueva York, Routledge, 1999: 1-16. OrTIz, Fernando, El Huracán: su mitología y sus símbolos, Ciudad de México, Fondo de Cultura Económica, 1947.

PADILla LOZOYA, Raymundo, «Estrategias adaptativas ante los riesgos por huracanes en Cuyutlán, Colima y San José del Cabo, Baja California Sur», Tesis doctoral, Ciudad de México, CIESAS, 2014a.

Padilla Lozoya, Raymundo, «Representaciones en San Felipe de Jesús (santo patrono contra incendios y temblores)», en Aideé Arellano Ceballos y Carlos Ramírez Vuelvas (coords.), Imaginarios y representaciones sociales y culturales en transición, México, Universidad de Colima, 2014b: 96-129.

Padilla Lozoya, Raymundo, «Desastres en México y Filipinas, cicatrices históricas que unen a nuestras culturas», en Paulina Machuca y Thomas Calvo (coords.), México y Filipinas: cuatro siglos de historia compartida, México, Colegio de Michoacán, 2016: 58-77.

PÉREZ SAMPER, María de los Ángeles, «Alimentación y desastres naturales», en Armando Alberola Romá y Jorge Olcina (eds.), Desastre natural, vida cotidiana y religiosidad popular en la España moderna y contemporánea, Alicante, Universidad de Alicante, 2009: 131-208.

Petit-BReuilh SePúlvedA, María Eugenia, Naturalezay desastres en Hispanoamérica, la visión de los indígenas, Madrid, Sílex, 2006.

Petrich, Perla, «Las fiestas patronales en los pueblos del lago Atitlán (Guatemala)», en Antonio Garrido Aranda (coord.), El mundo festivo en España y América, Córdoba, Universidad de Córdoba, 2005: 263-272.

Quarantelli, E. L., What is a Disaster? Perspectives on the Question, Nueva York, Routledge, 1998.

QUENET, Gregory, «Earthquakes in early Modern France, from the Old Regime to the birth of a new risk», en Andrea Janku, Gerrit J. Sckenk y Franz Mauelshagen (eds.), Historical disasters in context, science, religion and politics, Londres, Routledge, 2012: 94-114. 
Roth SENEFF, Andrew, «Religiosidad y desastres», Relaciones: Estudios de Historia y Sociedad, 97 (2004): 11-16. Disponible en: http://www.colmich.edu.mx/ relaciones25/files/revistas/097/pdf/originales/01.pdf

SCHNEIDER, David M., «Typhoons on Yap», Human Organization, 16/2(1957): 10-15. Disponible en: http://www.jstor.org/stable/44124806

SCHWARTZ, Stuart B., «Hurricanes and the shaping of Circum-Caribbean Societies», The Florida Historical Quarterly, 83/4(2005): 381-409. Disponible en: http:// www.jstor.org/stable/30149583

SPILlius, James, «Natural disasters and political crisis in a Polynesian society», Human Relations 10/1 (1957): 3-27.

TAINTER, Joseph A., The collapse of complex societies, Cambridge, Cambridge University Press, 1988.

VAUCHEZ, André, Francis of Assisi, the life and afterlife of a Medieval Saint, Londres, Yale University Press, 2012.

VIAzzo, Pier Paolo, Upland communities, environment, population and social structure in the Alps since the sixteenth century, Nueva York, Cambridge University Press, 1989.

WACHTEL, Nathan, El regreso de los antepasados, los indios Urus de Bolivia, del siglo XX al XVI, ensayo de historia regresiva, México, Fondo de Cultura Económica/ Colegio de México, 2001.

ZSCHAU, Jochen y KÜPPERS, Andreas N., Early warning systems for natural disaster reduction, Berlin, Springer, 2003. 